\title{
LAZER E PARTICIPAÇÃO SOCIAL NA PERCEPÇÃO DA PESSOA COM DEFICIÊNCIA VISUAL
}

Recebido em: 27/01/2019

Aceito em: 10/10/2019

\author{
Maria Luiza Valeriano Martins Oliveira ${ }^{1}$ \\ Regina Yoneko Dakuzaku Carretta ${ }^{2}$ \\ Universidade de São Paulo (USP) - Campus Ribeirão Preto \\ Ribeirão Preto - SP - Brasil
}

RESUMO: O presente estudo teve como objetivo compreender a percepção de indivíduos com deficiência visual sobre o lazer e a participação social. Trata-se de um estudo qualitativo, transversal e exploratório que foi realizado com 11 indivíduos com deficiência visual, moradores e ex-moradores de uma associação em Ribeirão Preto (SP). Para a coleta de dados usou-se entrevista semiestruturada, sendo interpretada segundo análise de conteúdo temática. Foram consideradas quatro categorias prédefinidas para análise: O que é lazer?; Oportunidades de lazer para a pessoa com deficiência visual; Inclusão Social; e A percepção quanto à participação social. Ás percepções dos sujeitos entrevistados permitiu concluir que o lazer e a participação social são temas pouco desenvolvidos, e seria importante investir em intervenções que beneficiem essa população bem como na ampliação dos estudos desses temas.

PALAVRAS-CHAVE: Transtornos da Visão. Atividades de Lazer. Terapia Ocupacional.

\section{LEISURE AND SOCIAL PARTICIPATION IN PERCEPTION OF INDIVIDUALS WITH VISUAL DEFICIENCY}

\footnotetext{
${ }^{1}$ Departamento de Ciências da Saúde da Universidade de São Paulo (USP) - Campus Ribeirão Preto. Graduanda do Curso de Graduação em Terapia Ocupacional.

${ }^{2}$ Departamento de Ciências da Saúde da Faculdade de Medicina de Ribeirão Preto da Universidade de São Paulo (USP) - Campus Ribeirão Preto. Docente do Curso de Graduação em Terapia Ocupacional ${ }^{2}$ Departamento de Ciências da Saúde da Faculdade de Medicina de Ribeirão Preto da Universidade de São Paulo (USP) - Campus Ribeirão Preto. Docente do Curso de Graduação em Terapia Ocupacional Programa de Residência Multiprofissional em Atenção Integral à Saúde. Comissão de Gestão Ambiental USP Recicla.
} 
ABSTRACT: The present study aimed to understand the perception of individuals with visual impairment on leisure and social participation. It is a qualitative, transversal and exploratory study that was carried out with 11 visually impaired individuals, residents and former residents of an association in Ribeirão Preto (SP). For the data collection a semi-structured interview was used, being interpreted according to thematic content analysis. Four pre-defined categories were considered for analysis: What is leisure?; Leisure opportunities for the visually impaired; Social inclusion; and The perception of social participation. The perceptions of the subjects interviewed allowed us to conclude that leisure and social participation are underdeveloped themes, and it would be important to invest in interventions that benefit this population as well as in the expansion of studies on these themes.

KEYWORDS: Vision Disorders. Leisure Activities. Occupational Therapy.

\section{Introdução}

Disfunção consiste na ação própria ou natural de um órgão, aparelho ou máquina, que realiza suas devidas funções de maneira irregular. Sendo assim, o termo “disfunção visual” refere-se ao que se conhece como deficiência visual (RIBEIRO, 2014). De acordo com a Classificação Internacional de Doenças 11 (CID 11) (2018), o comprometimento da visão pode ser classificado em dois grupos com relação à acuidade visual: comprometimentos mais à distância e os mais de perto (OMS, 2018).

A deficiência visual pode ocorrer após doença, trauma ou envelhecimento e frequentemente observa-se uma combinação de pelo menos duas dessas causas, especialmente em pessoas mais velhas (WARREN, 2005). Segundo a Organização Mundial da Saúde (2018), globalmente, as principais causas de deficiência visual são: erros de refração não corrigidos, catarata, degeneração macular relacionada à idade, glaucoma, retinopatia diabética, opacidade da córnea e tracoma.

Sabe-se ainda que para além das condições físicas alteradas, há impactos no que diz respeito a fatores sociais e emocionais do indivíduo, segundo Ribeiro (2014) 
A perda da capacidade visual gera condições adversas, tanto em nível individual quanto coletivo. A cegueira dá origem a problemas psicológicos, sociais, econômicos e de qualidade de vida, pois implica perda de autoestima e de "status", restrições ocupacionais e consequente diminuição de renda, que por sua vez, produz dificuldades de sobrevivência (p.399).

O público alvo dessa pesquisa foi composto por um grupo de pessoas com deficiência visual, moradores e ex-moradores de uma instituição filantrópica que funciona como uma Organização Não Governamental (ONG), ou seja, sem fins lucrativos, localizada em um município no interior do estado de São Paulo.

A proposta deste estudo foi explorar a temática do lazer sob as perspectivas das pessoas com deficiência visual, afinal, como Farias e Servo (2005) defendem:

O lazer é um elemento constituinte da vida dos sujeitos, tão importante quanto qualquer outro direito básico e deve ser oferecido nas mais diversas possibilidades para que todos tenham opção de escolha e possam saber como utilizá-lo, seja para recrear, descansar, se desenvolver ou cuidar da saúde. Os sujeitos, ao participar das atividades de lazer, se relacionam afetiva e diferentemente com o mundo (p.203).

O lazer é a atividade escolhida livremente, apenas pelo prazer da atividade, com um mínimo de obrigações sociais e livre de restrições. As atividades de lazer permitem às pessoas satisfazer necessidades pessoais como as de se expressar ou criar, sentir-se capaz de fazer algo, relacionar-se com outras pessoas e ao ambiente e também necessidade de pertencer a uma comunidade e ser considerada parte dela (GLANTZ; RICHMAN, 2005).

Várias são as áreas que estudam o lazer, sendo algumas delas Administração, Arquitetura e Urbanismo, Antropologia, Ciência da Informação, Economia, Educação, Educação Física, Fisioterapia, Terapia Ocupacional, Psicologia, Serviço Social, Sociologia, Turismo, entre outras, abordando o tema sob diferentes aspectos (PINHEIRO;GOMES, 2011), entretanto, tal pesquisa visa utilizar-se da fundamentação 
da Terapia Ocupacional que afirma a importância da atividade humana ter um sentido e uma função na vida de qualquer pessoa. A partir desta definição então é que se conceitua a ocupação.

Ocupação segundo Gary Kielhofner, autor do Modelo da Ocupação Humana, são os vários tipos de atividades cotidianas nas quais as pessoas, grupos ou populações exercitam suas capacidades e geram experiências, típicas para cada ciclo de vida, enfocando na motivação para a ocupação, os padrões de rotina, a natureza do desempenho ocupacional e a influência do ambiente na ocupação, objetivando assim compreender o comportamento ocupacional e a disfunção ocupacional, a fim de que o profissional terapeuta ocupacional possa planejar a intervenção (DRUMMOND, 2014).

Neste estudo foram abordado as ocupações lazer e participação social, no qual a Associação Americana de Terapia Ocupacional (AOTA) definem como:

- Lazer: Atividade não obrigatória que é realizada durante o tempo livre, propiciando momentos de descontração e diversão (AOTA, 2015);

- Participação social: Envolvimento em atividades em que se obtêm interação bemsucedida ao nível da comunidade, da família e dos amigos (AOTA, 2015).

Levando em consideração o público alvo desta pesquisa, as escolhas e opiniões, na maioria das vezes, são determinadas pelos que convivem diretamente com elas. E no caso de algumas pessoas deste estudo, que estão institucionalizadas há muitos anos e sendo em sua maioria idosa, o exercício da escolha, da participação social, fica ainda mais limitado. Sendo assim, são objetivos dos terapeutas ocupacionais oferecerem a qualquer indivíduo reflexão sobre o significado em seus fazeres, como forma de desenvolvimento de sua autonomia, independência e realização pessoal (MARTINELLI, 2011). 
Lidar com o processo de envelhecimento, a deficiência visual e a institucionalização diminui as oportunidades dos indivíduos para exercer controle sobre suas tarefas diárias, incluindo oportunidades para realizar atividades de lazer e participação social. Isto leva frequentemente a uma diminuição no senso de competência, menor motivação e depressão (GLANTZ; RICHMAN, 2005). Torna-se objeto de trabalho do terapeuta ocupacional então, considerar as ocupações humanas envolvidas nessas atividades, buscando aprimorar o desempenho ocupacional desses adultos e idosos para que eles possam agir com autonomia e independência em todos os aspectos da vida diária, seja nos cuidados pessoais, trabalho, lazer ou participação social (GLANTZ; RICHMAN, 2005).

A participação social é uma ocupação que envolve a interação do indivíduo com o contexto em ele vive, incluindo ocupações que apóiem a interação do individuo com a comunidade, família bem como pares e amigos (AOTA, 2015). Segundo a Classificação Internacional de Funcionalidade, Incapacidade e Saúde (CIF), a restrição nesta ocupação é resultante da interação entre aspectos referentes à deficiência na estrutura e função do corpo, limitação em atividades cotidianas, histórias de vida dos sujeitos entrevistados, influências culturais tanto do indivíduo quanto sociais, entre outros aspectos (FARIA-FORTINI et al., 2017). Sendo assim, observa-se que o lazer pode constituir-se em um campo restrito de participação social aos deficientes visuais, ainda que, conforme a legislação em prol da inclusão social possa ter provocado melhorias nesta questão (SAITO,2010). O que se buscou com esta pesquisa foi trazer elementos que subsidiem a problematização das vivências dessa população em sociedade e as várias interferências que há no lazer e, por conseguinte no viver em conjunto. 
Este estudo teve como objetivo principal, identificar a percepção da pessoa com deficiência visual sobre o lazer e a participação social a partir da reflexão sobre a importância do lazer sob aspectos estudados pela Terapia Ocupacional às pessoas com deficiência visual, da identificação da problemática sobre a deficiência visual bem como as interferências desta no lazer, e também conhecer possíveis desdobramentos da institucionalização de pessoas com deficiência visual relacionados ao lazer.

\section{Procedimentos Metodológicos}

Trata-se de uma pesquisa de caráter qualitativo, transversal e exploratória, realizado em uma associação para deficientes visuais do interior de São Paulo, com 11 indivíduos, mulheres e homens com deficiência visual numa faixa etária acima de 18 anos, alguns institucionalizados e outros que já saíram da instituição, mas ainda são vinculados e por isso frequentam a Associação para favorecer a participação social. A autorização da associação foi obtida previamente, e esta pesquisa foi aprovada pelo Comitê de Ética em Pesquisa registrado pelo processo n ${ }^{\circ} 4454 / 2017$ e sob o CAAE: 66581717.4 .0000 .5440 .

O termo de consentimento livre e esclarecido (TCLE) foi disponibilizado com cópia em Braille para os indivíduos alfabetizados neste sistema de escrita tátil. E no caso de pessoa não alfabetizada nem na escrita quanto no sistema Braille, o sujeito identificou uma pessoa de confiança para a leitura do TCLE.

Foi utilizado um roteiro de entrevista semiestruturada abordando questões de lazer e participação social da pessoa com deficiência visual, que posteriormente foi analisado de acordo com a abordagem de análise de conteúdo temática segundo Minayo 
(2000). A Análise Temática de Conteúdo desdobra-se nas seguintes etapas: pré-análise, exploração do material ou codificação e interpretação dos dados coletados.

Esse tipo de abordagem escolhida aplica-se ao estudo da história, das relações, das representações, das crenças, das percepções e das opiniões, produto das interpretações que os seres humanos fazem de como vivem, constroem seus artefatos e a si mesmos, sentem e pensam (CAVALCANTE; CALIXTO; PINHEIRO, 2014).

As entrevistas foram transcritas tendo como critério a preservação das falas dos participantes; foram realizadas algumas correções, mas essas não alteraram o conteúdo das frases, preservando a mensagem. O anonimato dos sujeitos foi garantido, utilizandose dos códigos S1, S2, S3 até S11 para identificá-los.

$\mathrm{Na}$ análise, organizou-se sistematicamente os dados empíricos colhidos nas entrevistas, e, após exaustivas leituras, classificou-se as falas dos sujeitos em grupos, de acordo com as semelhanças encontradas nos discursos e também com as categorias prédefinidas pelas pesquisadoras.

O processo de análise dos dados permitiu a predefinição de quatro categorias: $\mathrm{O}$ que é lazer?; Oportunidades de lazer para a pessoa com deficiência visual; Você considera-se incluído socialmente? E por último, a percepção quanto à participação social.

Para complementar a discussão da categoria O que é lazer? Foram reunidas algumas falas dos sujeitos entrevistados acerca das atividades de lazer que faziam no passado, as que fazem nos dias atuais e aquelas que gostariam de fazer, como forma de propiciar reflexão acerca das atividades significativas de lazer para eles. 


\section{Quadro 1: Caracterização geral dos sujeitos}

\begin{tabular}{|c|c|c|c|c|c|}
\hline $\begin{array}{l}\text { Sujeitos da } \\
\text { pesquisa }\end{array}$ & Sexo & Idade & Escolaridade & Causa da DV & $\begin{array}{c}\text { Há quanto tempo } \\
\text { frequenta a } \\
\text { Associação? }\end{array}$ \\
\hline $\mathrm{S} 1$ & Feminino & 47 & $3^{\circ}$ ano primário & Congênita & 31 anos \\
\hline $\mathrm{S} 2$ & Masculino & 45 & $\begin{array}{l}\text { Curso superior } \\
\quad \text { (Letras) }\end{array}$ & Catarata Congênita & 14 anos \\
\hline $\mathrm{S} 3$ & Feminino & 57 & $\begin{array}{l}\text { Ensino fundamental } \\
\text { incompleto }\end{array}$ & Glaucoma Congênito & 31 anos \\
\hline $\mathrm{S} 4$ & Masculino & 55 & $\begin{array}{l}\text { Ensino médio } \\
\text { técnico incompleto }\end{array}$ & $\begin{array}{c}\text { Adquirida aos } 2 \text { anos de } \\
\text { idade (suspeita de } \\
\text { nefrite) }\end{array}$ & 53 anos \\
\hline S5 & Feminino & 65 & $\begin{array}{l}\text { Ensino fundamental } \\
\text { completo }\end{array}$ & $\begin{array}{l}\text { Glaucoma adquirido; } \\
\text { perdeu aos } 18 \text { anos }\end{array}$ & 35 anos \\
\hline S6 & Masculino & 38 & $\begin{array}{l}\text { Ensino médio } \\
\text { incompleto }\end{array}$ & Hidrocefalia aos 25 anos & 2 anos \\
\hline S7 & Masculino & 30 & $\begin{array}{l}\text { Ensino fundamental } \\
\text { incompleto }\end{array}$ & $\begin{array}{l}\text { Adquirida pós-parto } \\
\text { (incubadora) }\end{array}$ & 12 anos \\
\hline S8 & Masculino & 51 & $\begin{array}{l}\text { Ensino médio } \\
\text { completo }\end{array}$ & $\begin{array}{l}\text { Glaucoma adquirido; } \\
\text { perdeu aos } 40 \text { anos }\end{array}$ & 7 anos \\
\hline S9 & Feminino & 49 & $\begin{array}{l}\text { Ensino fundamental } \\
\text { incompleto }\end{array}$ & $\begin{array}{l}\text { Acidente com arma de } \\
\text { fogo aos } 27 \text { anos }\end{array}$ & 22 anos \\
\hline $\mathrm{S} 10$ & Feminino & 70 & $\begin{array}{l}\text { Ensino fundamental } \\
\text { incompleto }\end{array}$ & $\begin{array}{c}\text { Congênita, nervo óptico } \\
\text { atrofiado }\end{array}$ & 52 anos \\
\hline $\mathrm{S} 11$ & Feminino & 80 & $\begin{array}{l}\text { Ensino fundamental } \\
\text { incompleto }\end{array}$ & $\begin{array}{l}\text { Adquirida aos } 8 \text { anos } \\
\text { devido à conjuntivite } \\
\text { sem assistência }\end{array}$ & 50 anos \\
\hline
\end{tabular}

Fonte: Elaborado pelas autoras.

\section{Resultados e Discussão}

Participaram desta pesquisa 11 indivíduos, sendo 5 homens e 6 mulheres, numa faixa etária acima de 18 anos com deficiência visual, alguns institucionalizados e outros que já saíram da instituição, mas ainda vinculados a esta instituição, frequentando-a semanalmente.

Após a coleta e analise de todas as entrevistas, verificou-se os vários tipos de atividades de lazer que são significativas para cada indivíduo e a relação destas na ampliação da participação social, foi constatado também que há um empobrecimento das atividades de lazer devido às dificuldades de acesso comprovadas nas categorias 
abaixo descritas, mas principalmente na chamada "Oportunidades de lazer para o deficiente visual" em que é colocado sobre a falta de acessibilidade nos lugares, o desconhecimento da deficiência visual por parte da sociedade e as questões relacionadas a institucionalização e a dependência de voluntários para realização de atividades internas e externas, fatores estes que dificultam o pleno exercício dessa ocupação por esta população.

\section{O que é Lazer?}

Os resultados deste estudo evidenciaram o lazer conceituado como um conjunto de atividades livremente escolhidas, agradáveis, que nos fazem "sair da rotina" (FARIA; MOTTA, 2012), como pode ser observado nas referências discursivas abaixo.

Ah! Lazer pra mim é tudo aquilo que é diversão sabe? (...) relaxa, que traz alegria, que traz uma harmonia, (...) uma coisa que a gente esquece de todas as coisas né (...) (S1).

(...) lazer é uma liberdade né, você fazer o que der na cabeça (...) (S6).

(...) é um motivo de assim é (...) de felicidade né que (...) um dia que você não vai ficar só naquela rotina, fechado, dentro de casa (...) (S9).

Falar em lazer implica pensar em vários conceitos. Além deste acima citado, sob a perspectiva de uma atividade livre, que não tenha um fim específico e sirva apenas para diversão, pode-se verificar também nas entrevistas, que o lazer é algo que pode envolver aspectos educativos como o de possibilitar participação cultural e rompimento de barreiras socioculturais (faixa etária, gênero, estereótipos, etc.) verificadas para o seu efetivo exercício (MARCELLINO, 2001).

(...) lazer pra mim é tudo aquilo que te leva ao entretenimento, ao divertimento enfim, né...tudo aquilo que te leva ao divertimento e 
também com utilidade, porque também todo o divertimento tem que ser útil pra alguma coisa, tem que ter um fim...eu acho (S2).

(...) meu lazer é fazer tudo diferente, ter uma coisa diferente pra dar um sentido na minha vida (...) (S4).

A partir dessas duas falas acima se entende o lazer como objeto, isto é, como forma de interpretação das ações sociais que incorporam sentidos das condutas, em outras palavras, adquire valor e assim define as condutas humanas na sociedade. O lazer re-significa as atividades do cotidiano, dando a estes elementos mais uma forma de interpretá-lo socialmente (ALMEIDA; GUTIERREZ; MARQUES, 2012).

Nas entrevistas foi possível destacar alguns aspectos com relação ao exercício do lazer. Observou que as atividades de lazer realizadas individualmente caracterizamse por ser atividades de leitura, ouvir música, assistir televisão, escutar palestras. Contudo, algumas atividades que envolvam passeios, viagens, dança, idas à clubes, restaurantes, são realizadas de forma coletiva, em grupo.

(...) quando eu enxergava eu gostava muito de ver filme, mas com a perda da visão isso pra mim perdeu um pouco o sentido, hoje o meu lazer é mais livro mesmo, eu gosto mais de ler e de escutar palestras (...) (S8).

(...) já fui em clubes, já fui em festas, (...) há toda uma questão social envolvida nisso, os grupos que a gente frequenta, de festas, clubes, é...restaurantes, cinema, parques de diversão, então assim (...) a gente estando inserido, logicamente (...) vamos participar ativamente ou sempre procuramos participar ativamente (...) (S2).

Assemelham-se também as atividades de lazer que alguns sujeitos identificaram como algo que têm vontade de realizar, mas ainda não fizeram. Em vários discursos aparece o desejo aparentemente simples de apreciar a natureza, ir às fazendas, cachoeiras, praias, fazer uma trilha. 
(...) adoro a natureza... gosto de fazer e nunca fiz assim, faço na mente só porque escuto os outros contar, na trilha, andar assim (...) (S11).

(...) gostaria muito de conhecer uma fazenda, que tivesse gado, se a gente pudesse pôr a mão, eu tenho muita vontade de conhecer uma vaca, um boi, eu não conheço (...) (S1).

(...) eu tenho vontade de conhecer (...) paisagens, uma cachoeira por exemplo, é bonito você ver uma cachoeira, deve ser muito bonito aquela água caindo de metros de altura, deve ser muito bonito, sabe (...) (S2).

Dentre os entrevistados houve um discurso que se destacou a respeito da apreciação a natureza: (...) a natureza é feita pra ser vista e não tocada muitas vezes (...) mas infelizmente estamos privados momentaneamente pela falta da visão, mas tenho vontade sim (S2). O que podemos observar foi o desejo de conhecer paisagens naturais, passear e desbravar lugares independente da condição visual, afinal não é porque eles estão desprovidos deste sentido que significa que eles não possam usufruir deste tipo de lazer.

O que falta muitas vezes é a diversificação dos estímulos em tudo o que nos é mostrado e vivenciado. Ao pensarmos em um ambiente com pássaros, cachoeiras, e com um jardim de flores não iremos focar somente em olhar (sentido da visão) através das variedades de elementos. Além de formas e cores, outros sentidos devem ser explorados: na audição com o som de pássaros, sinos de vento e fonte de água caindo sobre as pedras; no cheiro (olfato) de aroma de flores e plantas e no paladar (gustação) sentindo o gosto de plantas comestíveis, por exemplo. O toque (tato) nos elementos dessa paisagem, pedras, plantas, água, sentindo diversas texturas.

Ainda sobre as dificuldades acerca do acesso ao lazer à população deste estudo, destaca-se uma fala que representa muito das condições às quais estão submetidos os sujeitos idosos e institucionalizados, não só desta Associação a que se refere a pesquisa, mas como própria consequência desse processo de institucionalização: 
Sabe um lugar pra ir aqui que eu sempre tive vontade e eu nunca tenho a oportunidade? (...) É de ficar um pouco na praça, ali no calçadão (...) às vezes quando eu saio, eu saio sempre com voluntário, com pessoas (...) elas tão sempre com pressa (...) aí eu passo ali no calçadão, às vezes tá tocando umas músicas bonitas (...) tenho vontade de sentar ali perto e sentir aquela brisa em mim e ficar ali pensando, comendo pipoca...essas bobeiras aí que eu gosto (S5).

Mais uma vez a fala acima se refere a um desejo muito simples de ser realizado, mas por vezes, além da condição fragilizada advindas do processo de envelhecimento, da deficiência visual e principalmente a dependência de voluntários para a locomoção em locais externos à instituição, dificultam o acesso a esses momentos prazerosos que S5 citou. O que podemos verificar é que os indivíduos institucionalizados vivem em um ambiente de rotinas, um lugar compartilhado sob os limites das regras institucionais, sendo assim, o sujeito não exerce sua autonomia em ocupações subjetivas como é o lazer.

Diante das questões levantadas neste tópico de discussão sobre o lazer, analisadas como um dos campos de estudo da Terapia Ocupacional, e segundo a fala de S1 quando the é perguntado sobre quais eram suas atividades de lazer: (...)o único lazer que a gente tem aqui é quando a gente tá aqui na sexta feira, com o grupo. Este grupo foi desenvolvido através de um projeto de extensão universitária em que o bolsista, graduando do curso de Terapia Ocupacional, tinha como objetivo propor ações na Associação que buscassem ampliar a participação social e o envolvimento com atividades de lazer. Identificamos então que o lazer pode ser sim usado como ferramenta para facilitar as relações interpessoais, a autonomia dos sujeitos, desenvolvimento de interesses e da participação social. Cabe ao terapeuta ocupacional nestas instituições identificar as demandas para o pleno exercício desta ocupação humana, como foi feito 
pelos graduandos participantes deste grupo em conjunto com as Assistentes Sociais que trabalham na instituição.

\section{Oportunidades de Lazer para a Pessoa com Deficiência Visual}

$\mathrm{Na}$ análise das falas foi possível observar que eles constataram terem oportunidades de lazer, porém muitas das vezes estas são limitadas. Dentre as dificuldades mais citadas como fatores importantes para comprovar as poucas oportunidades que os entrevistados relataram estão: a falta de acessibilidade dos lugares que ofertam o lazer no município e o desconhecimento da deficiência visual pela sociedade. Entende-se então que independente da institucionalização essas percepções sobre o lazer limitam as oportunidades para o exercício da sua prática (MARTINELLI, 2011), visto que mesmo aqueles sujeitos entrevistados que não moram mais na Associação, conquistando maior independência e autonomia, também identificaram as mesmas dificuldades, acima citadas e comprovadas pelos discursos abaixo:

(...) a acessibilidade é mínima, as oportunidades são menores ainda(...) (S8).

(...) a sociedade está muito desinformada com relação aos cegos, então por isso há falta de oportunidades pra gente poder ter mais lazer, eu acho (...) (S2).

Segundo o Manual do Instituto Brasileiro de Turismo (EMBRATUR), a acessibilidade é definida como a condição para utilização, com segurança e autonomia, total ou assistida, dos espaços, mobiliários e equipamentos urbanos, das edificações, dos serviços de transporte e dos dispositivos, sistemas e meios de comunicação e informação, por pessoa com deficiência ou com mobilidade reduzida (BRASIL, 2006). Entretanto, o que temos na teoria não corresponde com o que vemos na prática, muitas das vezes o desconhecimento do que é a deficiência visual, por exemplo, como foi 
abordado pelos sujeitos como um dos problemas que inviabilizam as oportunidades de lazer, também constitui uma barreira no momento de analisarmos a acessibilidade. Ou seja, algumas mudanças arquitetônicas em um ambiente podem ser apropriadas para um indivíduo com dificuldades de locomoção, mas podem não afetar em nada a acessibilidade do ambiente para um indivíduo com deficiência visual (FARIA; MOTTA, 2012).

Dessa forma, tais iniciativas não são suficientes para garantir às pessoas com deficiência acesso ao lazer pois parece faltar principalmente o treinamento para que as pessoas possam atender a esse público. A acessibilidade é uma das questões centrais para a qualidade de vida e o pleno exercício da cidadania pelos sujeitos desta pesquisa bem como as outras pessoas com qualquer tipo de deficiência. Sendo assim, as dificuldades de locomoção nas vias públicas e de acesso aos transportes públicos, além de inúmeros constrangimentos, frequentemente inviabilizam o exercício desses indivíduos dos direitos à educação, à saúde, ao trabalho e também do lazer e participação social, ocupações em destaque neste estudo (CARVALHO, 2017).

Em apenas um discurso o lazer se configura como uma atividade em que o sujeito exerce de forma constante e sem muitas dificuldades, justificando sua condição devido a oportunidade que ele teve de sair da instituição e ter uma condição socioeconômica melhor que lhe permita realizar suas atividades preferidas de lazer, que é viajar.

Fiz muita coisa, mas o que mais faço assim no geral é viajar (...) Já conheço alguns países como Portugal, Espanha, França, Suíça, Itália e os Estados Unidos (S4).

(...) eu tenho certa condição de realizar esses lazeres, então eu não sei se as pessoas têm essa condição assim, eu imagino que se tiverem, se tiver possibilidade e condição seria interessante eles fazerem, porque eles vão ter um conhecimento, um sentido diferente da forma de viver, 
da forma de compreender o mundo, das pessoas (...) pro deficiente é muito mais difícil então eles não têm tanto acesso aos lazeres (S4).

O relato de S4 traz a questão socioeconômica como possível barreira para a realização desta ocupação, porém constatamos acima que as atividades de lazer descritas pelos outros sujeitos, muitas delas não dependem grande aporte financeiro para serem realizadas, como é por exemplo passear pelas ruas, ir a uma praça, conhecer uma fazenda, entre outros.

\section{Inclusão Social}

Segundo Mazzotta e D`Antino (2011), a inclusão social é um conjunto de medidas para garantir que todas as pessoas participem da sociedade igualmente de forma ativa. A necessidade de inclusão existe quando uma sociedade tem entre seus cidadãos pessoas que não usufruem de direitos que seriam devidos a todos. No caso dessa pesquisa, seguimos as percepções das pessoas com deficiência visual que trouxeram se sentir incluídos porque eles se propõem a conquistar seus direitos, tal como foi idealizado pelo conceito acima e definido socialmente.

Sim. Eu me incluí (S8).

Sim (...) se a gente achar que a gente não é incluso na sociedade a gente vai ficar sempre pra baixo (...) (S9).

(...) eu tento me incluir de certa forma na sociedade porque sei que a sociedade não vai me incluir nunca, então esse tema de inclusão é um tema que realmente não me agrada, porque é uma coisa que é utopia, é uma coisa que é falsa (...) os deficientes em relação a sociedade são minoria então eles que tem que se incluir na sociedade, como a sociedade é a maioria eles não se preocupam porque eles não vivem aquele....aquela situação (S4).

Nas falas acima, percebe-se que há a confirmação da inclusão, porém sob perspectiva unilateral, ou seja, a pessoa com deficiência é quem tem que buscar se 
incluir na sociedade senão estará excluída. Contudo, ao entendermos a inclusão social como algo que ocorre na vida social em algum espaço instituído ou estruturado, seja na família, na escola, no parque, na empresa ou em qualquer outra forma de organização social (MAZZOTTA; D'ANTINO, 2011), analisamos o termo sob a perspectiva coletiva e não só individual, que envolva o exercício da cidadania, verificado no discurso abaixo.

Eu me sinto incluído sim, a partir do momento que eu faço parte da sociedade. E como que eu faço parte da sociedade? De ' $n$ ' formas, por exemplo, sou eu quem vota nesses políticos que hoje estão nos roubando, sou eu que aplaudo muitos políticos que fazem coisas boas, embora hoje em dia isso parece estar meio em extinção, mas sou eu que manifesto e protesto nas ruas contra essa gente que está massacrando nosso dinheiro, tá acabando com a Petrobrás, sou eu que peço remédios em farmácia popular porque eu não posso comprar, sou eu que pago impostos IPTU, INSS, e tantos outros, sou eu que faço parte da sociedade no momento em que sou convidado a participar de reuniões pra decidir o que vai ser do nosso bairro, por exemplo, o que a gente pretende em nosso bairro, em nossa cidade e em nosso país. Então, eu me sinto incluído socialmente sim, claro que há essa exclusão social, mas eu me considero incluído (S2).

É interessante observar que S2 se reconhece como cidadão que cumpre vários papéis perante a sociedade justificando sua inclusão, porém não retira de seu discurso a existência da exclusão social como barreira no exercício de sua participação social. Segundo Beltrame et al. (2018) o que se observa é que existe do ponto de vista histórico, uma territorialização do espaço urbano que marca a relação da pessoa com deficiência com a sociedade. Sendo assim, a cidade enquanto espaço para o lazer e participação social segrega as pessoas com deficiência, pois a sociedade não se preparou para receber essas pessoas nos espaços de convívio.

Ao pensarmos no campo profissional da Terapia Ocupacional, podemos refletir e pensar em estratégias para modificar essa situação já historicamente pré-definida. Para 
embasar a prática desse profissional junto à população com deficiência, é necessário entender a inclusão social no lazer através da conceituação do termo justiça ocupacional (AOTA, 2015), que assegura que todos os indivíduos tenham suas ocupações diárias preservadas. Nesse sentido, o terapeuta ocupacional preocupa-se com as questões éticas, morais e cívicas dos ambientes e contextos de seus clientes a respeito dessa pesquisa, do lazer e da participação social dos deficientes visuais, reconhecendo os aspectos de injustiça ocupacional e apóia políticas, ações e leis que permitam que as pessoas se envolvam nessas ocupações e que estas enfim possam ter significado em suas vidas.

\section{Percepção quanto à Participação Social}

Diante dos dados coletados nas entrevistas, a participação social é concebida como envolvimento em uma situação da vida que está vinculado ao cotidiano e que favoreça a constituição de uma rede social de suporte. Desse modo, a participação social dos entrevistados apresentou por um lado, caráter micropolítico, caracterizado pela rede de relações estabelecidas no cotidiano do sujeito e de sua família, e por outro, um caráter macro político, caracterizado pela participação em diferentes instâncias sociais, às quais possam estar vinculados de alguma forma (SAITO, 2010).

Nesse sentido, como exemplo de caráter micropolítico, podemos verificar os discursos abaixo referentes à participação social em festa de familiares.

(...) cê fica lá parecendo uma árvore de natal sabe? Cê fica lá sentada, não pode sair andando, não pode conversar, as pessoas parece que tem um certo receio de vir conversar com você e você fica assim meio deslocado né? (S1).

(...) esse negócio de festa é um negócio muito interessante, eu até gosto de ir em festas só que festa tem um problema muito sério pra mim. Eu vou nas festas e eu to no meio de muita gente, mas eu me sinto só (...) mesmo que eu tiver com 50 pessoas eu vou estar sozinho (S4). 
Estes exemplos mostram certo déficit da participação social dentro do núcleo familiar destes entrevistados, o que nos remete novamente as reflexões sobre a exclusão social da pessoa com deficiência visual. É preciso se atentar a essas questões para que as relações interpessoais com os familiares desses indivíduos não contribuam para a passividade e o sentimento de não pertencimento em situações que envolvam o sujeito e a família.

Verificou-se em caráter macropolítico, participação social dos entrevistados em entidades voluntárias, asilos, hospitais e também em órgão público municipal que responde pelos direitos das pessoas com deficiência.

(...) já participei de várias ações do CVU (Centro de Voluntariado da USP) (...) eu já participei de ações dentro de asilos, lá na minha cidade eu já toquei no hospital público pra pessoas doentes né? Acamadas (...) então tudo que eu vou fazer, eu não procuro ficar restringindo aquela coisa do mundo do deficiente né (...) eu tento ampliar mais a minha vida (S8).

Neste discurso, o sujeito amplia sua participação social em contextos que não o limite a convivência com seus pares, e consegue desempenhar bem seu papel nesta ocupação independente do ambiente e das pessoas com quem se relaciona.

Os sujeitos colocaram também que não há engajamento no que diz respeito ao Conselho Municipal que responde pelos seus direitos devido à pouca organização deste e relatam que o mesmo não lhes ajuda, como podemos verificar nesta fala: (...)lá só participei quando teve votação né(...). Que tinha que escolher lá as pessoas que gerenciam (...). Fala que vai melhorar pra gente, não melhora nada. Só piora (...) (S6). Contudo, ao entendermos a participação social como vínculos que construímos cotidianamente, além da conscientização social acerca do preparo para receber e respeitar as diferenças, a luta diária de se fazer incluir e sentir-se incluído também 
precisa passar por cada indivíduo como algo a ser conquistado no coletivo. Afinal, participação social não é só algo reproduzido pela sociedade como também é produzida e transformada por ela (BELTRAME et al., 2018).

\section{Considerações Finais}

Esta pesquisa possibilitou identificar as questões entre a deficiência visual, os aspectos sociais e as influências sobre o lazer. Neste estudo junto às pessoas com deficiência visual, as percepções que eles trazem quanto ao exercício desta ocupação nos faz refletir sobre a importância de se investir em intervenções, desde ações de profissionais, dos serviços de atenção a esta população, da sociedade em geral até criação de políticas públicas e ampliação de estudos sobre o lazer e a participação social das populações com deficiência.

Pensar no desenvolvimento do lazer para esta população requer pensar em saídas eficazes para permitir a efetiva participação social junto a estas atividades tanto de forma individual quanto no coletivo. O projeto de extensão universitária citado neste trabalho foi uma ótima proposta para possibilitar, sob o olhar da Terapia Ocupacional, aos indivíduos que frequentam a Associação, diversificação da rotina, o poder de escolha, autoconhecimento sobre seus interesses, entre outros aspectos do lazer que não exige elevado custo financeiro, supervalorização de recursos visuais ou altas habilidades para a realização desta ocupação que como qualquer outra apresenta sentido e função na vida de todas as pessoas.

\section{REFERÊNCIAS}

ALMEIDA, M. A. B.; GUTIERREZ, G.L.; MARQUES, R. Qualidade De Vida: definição, conceitos e interfaces com outras áreas de pesquisa. São Paulo. Escola de 
Artes, Ciências e Humanidades - EACH/USP. 2012. Disponível em: http://each.uspnet.usp.br/edicoes- each/qualidade_vida.pdf. Acesso em: 02 out 2019.

AOTA. Estrutura e prática da Terapia Ocupacional: domínio e processo. Rev Ter Ocup Univ São Paulo; jan.-abr. 2015.

BELTRAME, A.L.N, et al. A cidade, o lazer, e a pessoa com deficiência: entre a invisibilidade e emergência da participação social. Licere, Belo Horizonte, v.21, n.2, jun. 2018. Disponível em: http://seer.ufmg.br. Acesso em: 10 dez. 2018.

BRASIL. Ministério do Turismo. Secretaria Nacional de Políticas de Turismo. Turismo e acessibilidade: manual de orientações / Ministério do Turismo, Coordenação - Geral de Segmentação. 2. ed. Brasília: Ministério do Turismo, 2006. 294 p.

CARVALHO, A. J. A importância do transporte público e da acessibilidade como meios de acesso a direitos de cidadania das pessoas com deficiência : o caso dos cadeirantes de Franca-SP : [s.n.], 2017. 164 p. Dissertação (Mestrado Profissional Políticas Públicas). Universidade Estadual Paulista, Faculdade de Ciências Humanas e Sociais. 2017.

CAVAlCANTE, R.B; CALIXTO, P.; PINHEIRO, M.M.K. Análise de conteúdo: considerações gerais, relações com a pergunta de pesquisa, possibilidades e limitações do método. Inf. \& Soc.: Est., João Pessoa, v.24, n.1, p. 13-18, 2014. Disponível em: http://www.periodicos.ufpb.br. Acesso em: 10 dez. 2018.

DRUMMOND, A. F. Fundamentos da Terapia Ocupacional. In: CAVALCANTI, A.; GALVÃO, C. Terapia Ocupacional: Fundamentação \& Prática. Rio de Janeiro: Guanabara Koogan, p.10-17, 2014.

FARIA-FORTINI, I. et al. Caracterização da participação social de indivíduos na fase crônica pós-acidente vascular encefálico. Rev Ter Ocup Univ São Paulo, jan.abr.;28(1):71-8, 2017.

FARIA, M. D.; MOTTA, P. C. Pessoas com Deficiência Visual: barreiras para o lazer turístico. Turismo em Análise, v. 23, n. 3, p. 691-717, 2012.

FARIAS, S. R. R.; SERVO, M. L. S. Representação social, lazer, e mulheres portadoras de cegueira congênita. Rev. baiana saúde pública, v.29, n.2, p. 200-213,2005. Disponível em: http://bases.bireme.br . Acesso em: 25 jul. 2016.

GLANTZ, C.H.; RICHMAN, N. Atividades de lazer. In: PEDRETTI, L.W.; EARLY, M.B. Terapia Ocupacional: Capacidades práticas para as disfunções físicas. 5. ed. São Paulo, p. 268-275, 2005.

MARCELlinO, N. C. (Org.) Lazer \& esporte: políticas públicas. 2. ed. Campinas: Autores Associados, 2001.

MARTINELLI, S. A. A importância de atividades de lazer na terapia ocupacional. Cadernos de Terapia Ocupacional da UFScar, São Carlos, v. 19, n.1, p. 111-118, 
2011. Disponível em: https://www.cadernosdeterapiaocupacional.ufscar.br. Acesso em: 25 jul. 2016.

MAZZOTTA, M.J.S.; D'ANTINO, M.E.F. Inclusão social de pessoas com deficiências e necessidades especiais: cultura, educação e lazer. Saude soc. [online], v.20, n.2, p.377-389, 2011.

MINAYO, M. C. S. O desafio do conhecimento: pesquisa qualitativa em saúde. 7. ed. São Paulo: Hucitec, 2000. 269 p.

OMS. Visual Impairment and Blindness. UN oficial report Fact Sheet $\mathbf{n}^{\mathbf{0}}$ 282. 2018. Disponível em: http://www.who.int/en/news-room/fact-sheets/detail/blindness-andvisual-mpairment . Acesso em: 10 dez. 2018.

PINHEIRO, M.F.G; GOMES, C.L. A temática do lazer em cursos de graduação da área da saúde. Belo Horizonte, Motriz: Rev. Educação Física, v.17, n.4, p.579-590, 2011. Disponível em: http://www.scielo.com.br. Acesso em: 25 jul. 2016.

RIBEIRO, L. B. Disfunção Visual. In: CAVAlCANTI, A.; GALVÃO, C. Terapia Ocupacional: Fundamentação \& Prática. Rio de Janeiro: Guanabara Koogan, p.399413, 2014.

SAITO, C. M. Atividade de lazer: tessitura de espaços para a alteridade [dissertação]. São Paulo: Faculdade de Medicina da Universidade de São Paulo, 2010. Disponível em: https://www.teses.usp.br/teses/disponiveis/5/5163/tde-04112010-173800/en.php Acesso em: 25 jul. 2016.

WARREN, M. Avaliação e tratamento de deficiências visuais. In: PEDRETTI, L.W.; EARLY, M.B. Terapia Ocupacional: Capacidades práticas para as disfunções físicas. 5. ed. São Paulo, p. 405-442, 2005.

\section{Endereço das Autoras:}

Maria Luiza Valeriano Martins Oliveira

Rua José Picerni, 431 - Jd. Panorama

São José do Rio Preto - SP - 15.091-200

Endereço Eletrônico: maluvmo08@gmail.com

Regina Yoneko Dakuzaku Carretta

Av. Bandeirantes, 3.900 - Monte Alegre

Ribeirão Preto - SP - 14.049-900

Endereço Eletrônico: reginadc@fmrp.usp.br 